\title{
FAUNAL TURNOVER AND PHYL,OGENY OF NEOGENE CARIBBEAN BRAIN CORALS (SCLERACTINIA: FAVIIDAE)
}

JOHNSON*, Kenneth G, Department of Geology and Applied Geology, The University of Glasgow, Glasgow G12 8QQ, UK.

Documenting patterns of long-term faunal change is an important application of paleontological data. However, fossil occurrences are typically poorly sampled, and inconclusive or even misleading results can emerge from analyses which are not designed to consider the effects of sampling bias. Stratigraphic evidence has been widely used to test hypotheses of phylogeny, and phylogeny can be used to assess the role of uneven or incomplete sampling in the analysis of faunal change. Combining stratigraphic and phylogenetic data in an evolutionary tree will usually require interpretations of 'ghost lineages' and hypothetical range extensions and can help highlight periods of relatively poor sampling. Estimates of rates of taxonomic change can change when phylogenetic information is included in an analysis of diversity patterns.

Previous analysis of occurrences of Miocene to Recent Caribbean reef coral species indicates significant species turnover during Late Neogene time. The goal of this study is to test the hypothesis of accelerated Plio-Pleistocene faunal change by adding phylogenetic information to the analysis. The complete reef coral fauna includes over 170 species, so a stable phylogeny has been inferred for the subset of taxa which experience most rapid turnover. Analysis of extinction susceptibility suggests that the appearance and subsequent extinction of species characterized by small, short-lived colonies is the main mode of faunal change. These taxa include the Faviid genera Caulastraea, Colpophyllia, Diploria, Favia, Manicina, Teleiophyllia, and Thysanus.

A phylogeny was inferred using cladistic techniques for 40 extinct and extant species. Twenty binary and multistate attributes were scored to describe the skeletal morphology characteristic of each taxon. In all, 64 character states were used. Although many characters are highly homology are homoplastic, some stable groups are clearly present. One group included all of the Colpophyllia species, another included Manicina, Teleiophyllia, and Thysanus species. As currently defined, both Favia and Diploria are paraphyletic stem groups. These relationships are substantiated by the geographic distributions of the groups. An evolutionary tree was created by integrating species ranges with phylogenetic relationships. When ghost lineages and the extinction of hypothetical ancestors are considered, the magnitude of estimates of species richness increase resulting in a decrease in estimates of proportional origination and extinction. However, the pattern of faunal change within the group remains largely unchanged, with accelerated origination during Late Miocene time followed by extinction during Late Pliocene and early Pleistocene time. 